\title{
Factors Influencing SME Outsourcing: Evidence from Romania
}

\author{
Ottilia GYÖRGY, ${ }^{1}$ Szilárd MADARAS ${ }^{2}$ \\ ${ }^{1}$ Sapientia Hungarian University of Transylvania (Cluj-Napoca, Romania) \\ Department of Economic Sciences \\ e-mail: gyorgyottilia@uni.sapientia.ro \\ ${ }^{2}$ Sapientia Hungarian University of Transylvania (Cluj-Napoca, Romania), \\ Department of Business Sciences \\ e-mail: madarasszilard@uni.sapientia.ro
}

\begin{abstract}
The present research, based on a national representative survey analysis of SMEs (that is, small and medium enterprises) from Romania, focuses on the main factors influencing companies' outsourcing. It considers the following dimensions of outsourcing: organizational characteristics, environmental characteristics, relational capabilities, and institutional networks. The results suggest that the younger the SMEs and the more stable their relationship with local institutions, the more likely is for them to adopt outsourcing solutions. Moreover, those SMEs that have secondary offices and have some cooperation with the state also rely on outsourcing. Our results suggest that sector membership also proves to be a significant factor in outsourcing. We find that the highest percentage of outsourcing was done in construction, industry as well as hotels and restaurants sectors.
\end{abstract}

Keywords: SMEs, outsourcing, business relationships

JEL Classification: L26, J24

\section{Introduction}

Romanian SMEs are in a special situation as being part of a transition economy, where in the past decade outsourcing solutions have considerably grown because the country has become a destination of IT outsourcing. While outsourcing in one sector (namely, in the IT) might be the norm, it takes different forms in others: relations with the local institutions or with the state and relationship capabilities for the Business Process Outsourcing (BPO).

Competitive advantage can be improved by outsourcing certain organizational capabilities, as the Resource-Based Theory (RBT) approach indicates (Gilley et al., 2004). Normally, a company's activity cannot cover everything, especially in the 
case of SMEs; in this sense, the Transaction Cost Economics (TCE) theory suggests that some activities, except the main activity, should be outsourced to achieve higher efficiency (McIvor, 2009; Belso-Martínez, 2010).

In this paper, the main factors influencing SMEs' outsourcing are grouped into four categories: organizational characteristics, environmental characteristics, relational capabilities, and institutional networks. From an organizational perspective, firm size and turnover are the used variables in Bennett and Robson (1999), Görg and Hanley (2004), Knudsen and Servais (2007), and Belso-Martínez (2010). Other indicators are the number of secondary offices and the existence of a written strategy as exogenous variables. The strategic planning of outsourcing was analysed in Arbaugh (2003) and Brewer et al. (2013). The environmental characteristics of SMEs include the sector membership, and the relational capabilities are described by the number of suppliers and the proportion of long-term contracts. BelsoMartínez (2010) included the institutional networks in their analysis. We have two indicators in this section, stable relationships with local institutions and the importance of cooperation with the state. The importance of this study is given by the novelty of the topic and the fact that no one has done a comprehensive research on SMEs' outsourcing in Romania before.

Section 2 of the paper reviews the SME outsourcing literature, Section 3 discusses the outsourcing in Romania, Section 4 considers the main factors influencing the Romanian outsourcing, Section 5 presents the results and discussion, and, finally, Section 6 concludes the paper.

\section{Literature Review}

The competitiveness of the global economy depends on the ability of companies to integrate into networks as well as on the availability of local networks. It is also important to note the fact that there are many other factors that come into play when companies try to integrate into the global production and supply chain.

Alguire et al. (1994) argued that firms which applied outsourcing on a global level gained important competitive advantages. A wide and comprehensive literature review on outsourcing can be found in Jiang and Qureshi (2006).

Belso-Martínez (2010) investigates the way companies are linked to local outsourcing decisions and the influence they have on new and previously established partnerships. The present study focuses on the importance of networks as well as on the internationalization of outsourcing production, taking into account the size of the companies. Today, SMEs play an increasingly important role not only in the success of local chains but also on international markets. To achieve this, companies tend to use the same methods: outsourcing, joint venture, opening market transactions, and subsidiaries abroad. As a result, we can see an 
increased international distribution of production, where the production process is distributed across countries.

Based on a survey analysis from Great Britain, Bennett and Robson (1999) demonstrated that the firm size is a significant control variable for SMEs' external business advisors, which they identified as professional specialist and generalist sources, contacts of customers and suppliers, social contacts, business associations, and government-sponsored agents.

Outsourcing means that certain activities become the responsibility of another company, and if the outsourcing is successful, the activity will be continued outside of the company. This strategy is usually implemented in stages, favouring near/ close partnerships to distant partnerships (Graf and Mudambi, 2005).

According to Heshmati (2003), outsourcing is a "different kind of corporate action related to all subcontracting relationships between firms and the hiring of workers in non-traditional jobs". On the one hand, outsourcing depends on the given industry, on the other hand, on the company's size. For example, larger companies have an advantage over smaller companies as they have a more favourable bargaining power with suppliers. At the same time, the more potential subcontractors competing with each other in a certain industry, the better the chance for the manufacturer to find a partner to whom they can outsource certain activities (Görg and Hanley, 2004). The outsourcing of service activities and knowledge-based activities is a business trend that will continue to evolve in the future. The reasons for outsourcing are numerous, but the most important of these are access to new markets or new technologies and lower labour costs (Stratman, 2008).

There is a difference between the types of partnerships that SMEs can enter depending on the industry, for example, in technology versus other more traditional industries. SMEs operating in the IT sector do not usually have all the necessary resources to develop their products; therefore, they frequently turn to outsourcing. In this sector, it is rare for a company to operate independently; instead, partnerships are created to increase efficiency. As opposed to the above, traditional industries do not necessarily have to rely on partnerships to achieve success; instead, their success depends on their ability to innovate.

On the other hand, the age of a given company is decisive in forming partnerships. Start-up SMEs tend to rely on partnerships to outsource, while established SMEs may be less interested in partnerships (Li and Qian, 2007).

The increased use of the value chain system in various industries and service sectors shows that the division of labour exists beyond the boundaries of the company, not just within the company. Outsourcing is nowadays a new business strategy. Several studies have shown that outsourcing contributes positively to an increase in the market value of large companies. Moreover, SMEs can reduce their costs and increase the efficiency of their business processes with outsourcing. Research has shown that offshoring offers an excellent opportunity for SMEs to 
become more profitable, thus overcoming resource constraints caused by size (Mohiuddin and Su, 2013).

Other studies show there is no clear correlation between outsourcing and costs, and such connection cannot be inferred from performance either. Outsourcing and its potential advantages are considered to be strategic options (Solakivi et al., 2011).

Interestingly, it is worth noting that, according to a study, outsourcing may have a negative impact on performance. This can happen if there is too much outsourcing activity. This means that with a certain level of outsourcing, uncertainty increases. At this level, making the right outsourcing decisions is becoming increasingly important. Outsourcing can be more costly if companies face greater market uncertainty (Kotabe and Mol, 2009).

Relational capability analysis is currently of great scientific interest, mainly due to the significant growth of strategic alliances and partnerships. Some studies suggest that there is a positive relationship between relational ability and willingness to outsource. The higher your chances with a company solving certain tasks with suppliers and customers, the greater the likelihood that you will continue to outsource activities. Nowadays, the development of relational capabilities and process integration can be one of the main operational aspects of a company. By doing so, it simplifies or eliminates activities that do not create enough value for it. In some sectors, cooperation is needed at every imaginable level to improve the efficiency and effectiveness of the processes (EspinoRodríguez and Rodríguez-Díaz, 2008).

There are a number of advantages to strategic outsourcing, a successful joint venture between parties. On the one hand, the most qualified workforce carries out the concrete activity, which results in a high-level division of labour. On the other hand, R\&D can be carried out at a much higher level of efficiency. Moreover, it is important to note that it might result in lower total costs for the company. Partners who engage in such partnerships gain mutual advantages and ensure long-term profitability (Zineldin and Bredenlöw, 2003).

There are studies that focus on the benefits and risks of outsourcing contracts. It is obvious that the right type of contract is the key to the success of outsourcing activities. Several studies bring evidence that a successful outsourcing operation is based on adequate contracting that guarantees the mutual fulfilment of interest between partners (Ngwenyama and Sullivan, 2007).

In the case of outsourcing, cooperation time is also a very important factor. In many cases, market uncertainties encourage long-term contracts. Teixeira (2013) examined whether a company works with short-term independent suppliers or prefers long-term contracts. The main difference between the two outsourcing systems is the uncertainty about the outsourcing price. In the case of outsourcing through long-term contracts, market price uncertainty is eliminated. The decision to outsource always involves a trade-off, especially with regard to the uncertainty/ 
evolution of the purchase price. Thus, long-term cooperation agreements serve as a risk management tool (Teixeira, 2013).

\section{Outsourcing in Romania}

In recent decades, Romania has become an attractive destination in the IT sector for both outsourcing and investment purposes. In the past 20-30 years, outsourcing in the IT sector in Romania has brought about enormous growth, so the existence of technology has played a key role in the country's economy. Romania does not offer the lowest prices in the field of outsourcing but has proven to be competitive in the areas of technical and soft skills. In addition to the advanced IT infrastructure, the fact that the workforce in this field is young, motivated, flexible, skilled, and has a good knowledge of foreign languages constitutes a great advantage. Boşcor and Băltescu (2014) found that the relatively underdeveloped infrastructure of Romania represents the most important disadvantage from an outsourcing perspective, in addition to which the government measures and national strategy should be implemented to attract more foreign investors.

In Romania, over the last 20 years, a number of companies have been established, enabling outsourcing to companies operating in the country. These small businesses were created by cooperating with world-renowned companies that entered the Romanian market (And one and Păvăloaia, 2010).

According to a KPMG study, Romania has been one of the most important destinations in Europe for the last 10 years, for example, in the field of IT outsourcing. The provision of global services continues to develop worldwide, making Romania an attractive business environment for investment companies. As a result, local BPO organizations are formed. According to research carried out by Asociația Business Service Leaders in Romania, more than 100,000 employees work in the outsourcing industry in Romania. ${ }^{1}$

However, according to the Kearney Global Service Location Index, Romania has been declining in recent years. This is due to the fact that in recent years ITO and Business Process Outsourcing (BPO) industries have faced major disruptions in digital transformation. The two strongest influencing factors are: automation and cyber security problems. According to the study, digital resonance influences location attractiveness.

Numerous studies address the fact that outsourcing can even be a viable option for SMEs and can bring competitive benefits, thus reducing their costs and increasing the efficiency of their business processes. Outsourcing is an

1 Source: http://www.outsourcingadvisors.ro/wp-content/uploads/2018/10/KPMG-Romania-as-thedestination-for-SSCs-and-BPO.pdf. 
excellent opportunity for SMEs to overcome size and capacity gaps, save money, and make them more profitable. Obviously, there may be different motivations for outsourcing (Mohiuddin and Su, 2013), but, in any case, SMEs can focus on their core competences and improve their overall competitiveness.

We analysed the factors influencing outsourcing for Romanian SMEs based on a national representative survey analysis from 2018, which contains 374 firms. In the survey, the presence of outsourcing agreements for enterprises becomes the dependent variable in our estimations, while the set of exogenous variables are grouped as follows.

The first group of factors, the SMEs' organizational characteristics, are the age of the firms, the number of employees, the turnover, the number of secondary offices, and the existence of a written strategy.

Firm size is decisive for outsourcing behaviour, as Bennett and Robson (1999) demonstrated. Smaller firms are more likely to adopt outsourcing solutions, as Görg and Hanley (2004) suggest. Belso-Martínez (2010) states that firm size is defined by the number of employees, which is an important factor in outsourcing. In the study of Knudsen and Servais (2007), the number of employees and turnover are included in SMEs' internationalization purchasing behaviour analysis.

Arbaugh (2003) examined whether there is a link between outsourcing practices, the existing strategy, and company size. He concluded that outsourcing choices and preferences can be greatly influenced by company size. The study suggests that outsourcing practices apply to the best-performing SMEs, thus allowing businesses to focus on their core activities.

Other studies have already examined the relationship between outsourcing and the existing strategy. What is particularly important is the driving force behind outsourcing in the existing strategy. The outsourcing goals formulated in the strategy can be of three types: cost reduction, focusing on core competencies, or growth (Brewer et al., 2013). According to them, outsourcing is an activity where managers can follow several strategies at the same time. Companies that have more outsourcing strategies can achieve greater cost savings than those which follow just one strategy. However, no matter what strategy they follow, there is usually a positive relationship between outsourcing and performance.

The existence of a written strategy was investigated using a four-scale question from "We do not have an elaborated strategy" up to "The company's activity is based on an elaborated strategy".

The environmental characteristics of outsourcing in our database represent the sector membership variable. A number of studies on outsourcing have tried to understand and explain the various factors that influence these activities, including the motivations and the risks. Outsourcing generally changes the structure of the sectors, enabling other companies to enter. This way, outsourcing companies in the sector allow other players in the sector to focus on their core business. In 
sectors where outsourcing becomes the norm, financial performance may improve (Harland et al., 2005).

Relational capabilities are described by two variables: the number of suppliers and the proportion of long-term contracts. In our database, the number of suppliers related to the main activity was examined using a four-scale division: " 1 . More than $80 \%$ of purchases come from a single supplier, 2 . We regularly have transactions with 5-20 suppliers, 3. We have 21 to 100 suppliers on a regular basis, 4." We have more than 100 suppliers. The proportion of long-term contracts with suppliers (over one year) from the total number of contracts with suppliers was analysed using a five-scale question regarding the percentage.

The institutional networks were investigated based on two variables: stable relationships with local institutions and the importance of cooperation with the state, the importance of which was measured using ten-scale questions in the questionnaire. Belso-Martínez (2010) suggested that institutional networks and supplier networks are important factors determining SMEs' outsourcing activities.

\section{Factors Influencing Outsourcing}

The organizational, environmental, and relational capabilities, the institutional network characteristics of outsourcing for the Romanian SMEs were described by the set of variables, whose statistics are presented below. One of the organizational characteristics as factors influencing outsourcing among Romanian SMEs, based on our national representative survey analysis from 2018, is the age of the firms. The average is 15.97 years, and the oldest firms have 27 years in the business, but regarding outsourcing we observed a decreasing tendency to adopt outsourcing, as the years pass. Particularly those firms that are older than 19 years tend to adopt outsourcing solutions in a lower proportion (see Table 1).

The size of firms is described by the number of employees and turnover, and a slight increase can be observed in outsourcing in the case of SMEs with more employees and higher turnover (see Table 1). The firms with more (SO) secondary offices do not appear to have more outsourcing partners compared to those with one to three offices. Those SMEs who have a clear and written business strategy seem to adopt outsourcing in a greater proportion (see Table 1).

The environmental characteristics of outsourcing in our database refer to sector membership. Outsourcing achieved higher proportions in industry and construction sectors than in others, while the lowest level of outsourcing was registered in agriculture, followed by services (see Table 2).

The relational capabilities were measured by the number of suppliers (NS) and the proportion of long-term contracts (PC). SMEs adopted outsourcing solutions in higher proportion where the number of suppliers was between 5 and 100 and the 
proportion of long-term contracts was between $40 \%$ and $80 \%$ of the total contracts with suppliers (see Table 2).

The institutional networks dimension of SMEs included stable relationships with local institutions (LI) and the importance of cooperation with the state (CS). Both variables suggest that those SMEs opt for outsourcing solutions which have stable institutional networks and evaluate the importance of this (see Table 2).

Table 1. The organizational characteristics as factors of outsourcing among Romanian SMEs

\begin{tabular}{|c|c|c|c|c|c|c|c|c|c|c|c|}
\hline Age & $1-3$ & $4-6$ & $7-9$ & $10-12$ & $13-15$ & $16-18$ & $19-21$ & $22-24$ & $25-27$ & Mean & Std. Dev. \\
\hline No & 0 & 3.13 & 4.17 & 4.35 & 6.45 & 2.63 & 21.88 & 11.11 & 10.2 & & \\
\hline Yes & 100 & 96.88 & 95.83 & 95.65 & 93.55 & 97.37 & 78.13 & 88.89 & 89.8 & & \\
\hline Total & 5.08 & 8.29 & 6.15 & 11.76 & 15.51 & 9.89 & 6.68 & 17.11 & 11.76 & 15.97059 & 7.218289 \\
\hline Empl. & $10-37$ & $38-64$ & $65-91$ & $\begin{array}{l}92- \\
118\end{array}$ & $\begin{array}{c}119- \\
145\end{array}$ & $\begin{array}{c}146- \\
172 \\
\end{array}$ & $\begin{array}{c}173- \\
199\end{array}$ & $\begin{array}{c}200- \\
226\end{array}$ & $\begin{array}{c}227- \\
250\end{array}$ & Mean & Std. Dev. \\
\hline No & 8.53 & 6.56 & 6.25 & 0 & 0 & 20 & 0 & 0 & 0 & & \\
\hline Yes & 91.47 & 93.44 & 93.75 & 100 & 100 & 80 & 100 & 100 & 100 & & \\
\hline Total & 68.98 & 16.31 & 4.28 & 3.21 & 1.07 & 2.67 & 1.34 & 1.07 & 1.07 & 40.52941 & 45.29342 \\
\hline $\begin{array}{l}\text { Turn- } \\
\text { over }\end{array}$ & 1 & 2 & 3 & 4 & 5 & 6 & & & & Mean & Std. Dev. \\
\hline No & 7.55 & 8.33 & 11.1 & 0 & 25 & 0 & & & & & \\
\hline Yes & 92.4 & 91.7 & 88.9 & 100 & 75 & 100 & & & & & \\
\hline Total & 88.5 & 6.42 & 2.41 & 1.34 & 1.07 & 0.27 & & & & 2904427 & 5284709 \\
\hline SO & 0 & $1-5$ & $6-10$ & $11-20$ & $\begin{array}{c}\text { More } \\
\text { t. } 20\end{array}$ & & & & & Mean & Std. Dev. \\
\hline No & 6.74 & 8.06 & 8.33 & 0 & 50 & & & & & & \\
\hline Yes & 93.3 & 91.9 & 91.7 & 100 & 50 & & & & & & \\
\hline Total & 23.9 & 66.5 & 6.43 & 2.68 & 0.54 & & & & & 2.55496 & 5.1421 \\
\hline $\begin{array}{l}\text { Strat- } \\
\text { egy }\end{array}$ & 1. & 2. & 3. & 4. & & & & & & Mean & Std. Dev. \\
\hline No & 11.54 & 8.91 & 6.87 & 5.56 & & & & & & & \\
\hline Yes & 88.46 & 91.09 & 93.13 & 94.44 & & & & & & & \\
\hline Total & 13.9 & 27.01 & 35.03 & 24.06 & & & & & & 2.692513 & .9873721 \\
\hline
\end{tabular}

Source: own calculations based on a national representative survey in Romania, 2018 


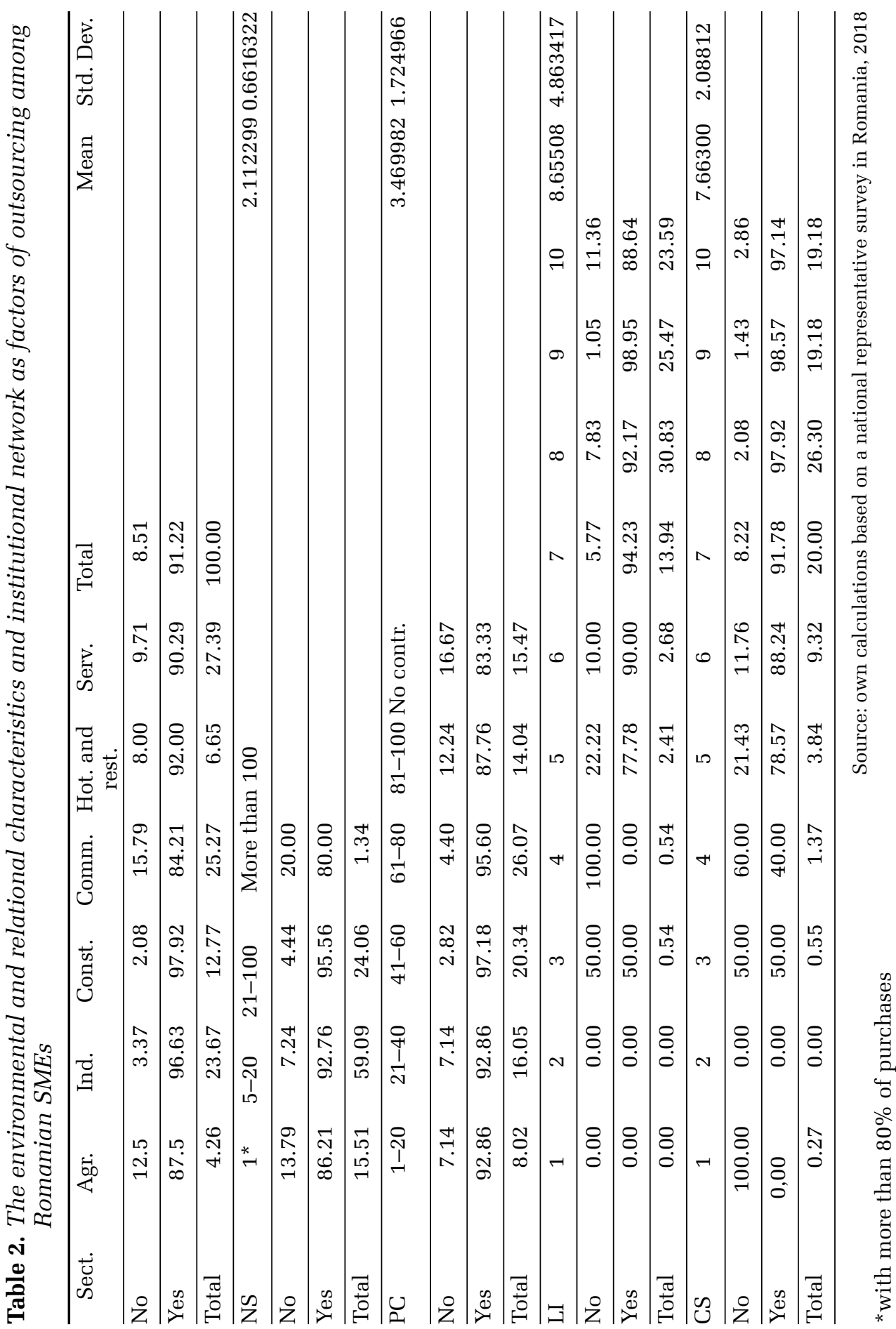


In the following, we focus on the relationship analysis between the variables included in the database using Spearman's correlation and then on the identification of the significant factors of outsourcing using logistic regression.

\section{Results and Discussion}

We calculated Spearman's correlation relationship between the variables included in the model. The most important Spearman's correlation results are as follows:

- between the outsourcing and the age of firms (Age) is -0.1319,

- between the outsourcing and sector membership (Sector) is -0.1154 ,

- between the number of employees (Empl) and Turnover is 0.4719,

- between the Turnover and the number of secondary offices (SO) is 0.2261 , and

- between the relationship with local institutions (LI) and cooperation with the state (CS) is 0.3293 (see Table 3).

Table 3. Spearman's correlations among the variables

\begin{tabular}{|c|c|c|c|c|c|c|c|c|c|c|c|}
\hline & Outsrc & Age & Empl & $\begin{array}{l}\text { Turn- } \\
\text { over }\end{array}$ & SO & $\begin{array}{l}\text { Stra- } \\
\text { tegy }\end{array}$ & Sector & NS & PC & LI & CS \\
\hline Outsrc & 1.0000 & & & & & & & & & & \\
\hline Age & -0.1319 & 1.0000 & & & & & & & & & \\
\hline Sig. & 0.0108 & & & & & & & & & & \\
\hline Empl & 0.0450 & 0.1514 & 1.0000 & & & & & & & & \\
\hline Sig. & 0.3863 & 0.0034 & & & & & & & & & \\
\hline $\begin{array}{l}\text { Turn- } \\
\text { over }\end{array}$ & -0.0216 & 0.0814 & 0.4719 & 1.0000 & & & & & & & \\
\hline Sig. & 0.6770 & 0.1167 & 0.0000 & & & & & & & & \\
\hline SO & -0.0569 & 0.1763 & 0.2536 & 0.2261 & 1.0000 & & & & & & \\
\hline Sig. & 0.2731 & 0.0006 & 0.0000 & 0.0000 & & & & & & & \\
\hline Strategy & 0.0699 & 0.0142 & 0.1312 & 0.0953 & 0.0781 & 1.0000 & & & & & \\
\hline Sig. & 0.1781 & 0.7851 & 0.0112 & 0.0661 & 0.1323 & & & & & & \\
\hline Sector & -0.1154 & -0.1171 & -0.1352 & -0.1229 & -0.0337 & 0.0212 & 1.0000 & & & & \\
\hline Sig. & 0.0259 & 0.0237 & 0.0089 & 0.0175 & 0.5170 & 0.6833 & & & & & \\
\hline NS & 0.0885 & 0.0715 & 0.0818 & 0.0875 & 0.0414 & 0.0664 & -0.0615 & 1.0000 & & & \\
\hline Sig. & 0.0877 & 0.1681 & 0.1149 & 0.0916 & 0.4256 & 0.2004 & 0.2363 & & & & \\
\hline PC & -0.1048 & 0.0789 & -0.0481 & 0.0178 & 0.0103 & -0.0251 & -0.0146 & 0.0634 & 1.0000 & & \\
\hline Sig. & 0.0432 & 0.1284 & 0.3541 & 0.7321 & 0.8428 & 0.6289 & 0.7781 & 0.2219 & & & \\
\hline LI & 0.0489 & 0.0854 & 0.0720 & 0.0938 & 0.0694 & 0.0489 & -0.0867 & 0.0567 & 0.0894 & 1.0000 & \\
\hline
\end{tabular}




\begin{tabular}{|c|c|c|c|c|c|c|c|c|c|c|c|}
\hline & Outsrc & Age & Empl & $\begin{array}{l}\text { Turn- } \\
\text { over }\end{array}$ & $\mathrm{SO}$ & $\begin{array}{l}\text { Stra- } \\
\text { tegy }\end{array}$ & Sector & NS & PC & LI & CS \\
\hline Sig. & 0.3459 & 0.0995 & 0.1653 & 0.0703 & 0.1814 & 0.3466 & 0.0943 & 0.2747 & 0.0848 & & \\
\hline CS & 0.1097 & 0.0771 & 0.1230 & 0.0339 & -0.0077 & -0.0705 & -0.1429 & -0.0231 & 0.0394 & 0.3293 & 1.0000 \\
\hline g & 0.0343 & 0.1373 & 0.0175 & 0.5141 & 0.8823 & 0.1741 & 0.0057 & 0.6565 & 0.4476 & 0.0000 & \\
\hline
\end{tabular}

Source: own calculations based on a national representative survey in Romania, 2018

The logistic regression estimation of the Romanian SMEs' outsourcing provides an identification tool for indicators which increase or decrease the probability of this process (see Table 4).

Table 4. Logistic regression analysis on the factors influencing outsourcing

\begin{tabular}{|c|c|c|c|c|c|c|c|}
\hline & & & \multicolumn{3}{|c|}{ Number of obs } & $=$ & 373 \\
\hline & & & \multicolumn{3}{|c|}{ Wald chi2(10) $=116.99$} & & \\
\hline \multicolumn{3}{|c|}{ Log likelihood $=-79.477049$} & Prol & hi2 = & 0.0000 & & \\
\hline Outsrc & Coef. & Std. Err. & $\mathrm{z}$ & $P>|z|$ & & & \\
\hline Age & -.2594394 & .0941699 & -2.76 & 0.006 & & & \\
\hline Empl & .2896764 & .2115458 & 1.37 & 0.171 & & & \\
\hline Turnover & -.3523267 & .2389263 & -1.47 & 0.140 & & & \\
\hline SO & -.0592103 & .0270993 & -2.18 & 0.029 & & & \\
\hline Strategy & .4033186 & .209649 & 1.92 & 0.054 & & & \\
\hline Sector & -.3169632 & .1380904 & -2.30 & 0.022 & & & \\
\hline NS & .5779818 & .3129864 & 1.85 & 0.065 & & & \\
\hline PC & .0032859 & .0085957 & -0.38 & 0.702 & & & \\
\hline LI & .4782675 & .1135238 & 4.21 & 0.000 & & & \\
\hline CS & -.0424659 & .0094775 & 4.48 & 0.000 & & & \\
\hline
\end{tabular}

Source: own calculations based on a national representative survey in Romania, 2018

The logistic regression model estimation results indicate the negative significant influence of the age of firms (Age) at $1 \%$, of the number of secondary offices (SO) at $5 \%$, and of the sector membership (Sector) at $5 \%$ on outsourcing. While the relationship with local institutions (LI) and the cooperation with the state (CS) have positive significant influence on outsourcing at $1 \%$ (see Table 4.), from an organizational perspective, results suggest that in the case of Romanian SMEs the number of employees (Empl), turnover (Turnover), and the presence of a written strategy do not have a significant effect on outsourcing. The SMEs' relational capabilities indicators, the number of suppliers (NS), and the proportion of long- 
term contracts (PC) do not have a significant influence on outsourcing decisions either (see Table 4).

The sector membership of SMEs has a significant influence on outsourcing decisions (see Table 4), and the results are in line with Harland et al. (2005).

The importance of institutional networks, as Belso-Martínez (2010) also proved, has a significant effect on outsourcing (see Table 4).

\section{Conclusions}

Using a national representative survey database from Romania (2018), containing 374 firms, we analysed the main factors influencing the Romanian SMEs' outsourcing, focusing on the organizational and environmental characteristics of firms and on their relational capabilities and institutional networks. The presence of outsourcing solutions in firms was the dependent variable in our database, which contained ten exogenous variables. Our results indicate that the age of firms, the secondary offices, sector membership, the presence of stable relationships with local institutions, and the importance of the cooperation with the state have a significant effect on Romanian SMEs' outsourcing.

Among the organizational characteristics, the SMEs' number of employees and turnover, i.e. the variables which were stated to have a significant influence on outsourcing in the literature (Bennett and Robson, 1999; Görg and Hanley, 2004; Knudsen and Servais, 2007; Belso-Martínez, 2010), proved to be unacceptable factors in the case of Romanian SMEs, while the age of companies and the number of secondary offices resulted to have negative significant influence. Secondly, regarding the environment, our results are in line with the findings of Harland et al. (2005) namely the sector membership. The sectors with the highest outsourcing in 2018 were construction, industry, and hotels and restaurants. Although we assumed that SMEs with higher relational capabilities are more likely to adopt outsourcing solutions, the two variables describing this dimension - namely, the number of suppliers and the proportion of long-term contracts - turn out not to be significant.

Our results are in line with Belso-Martínez (2010) regarding the importance of institutional networks in outsourcing. An important result in the case of Romanian SMEs is that local institutions and state cooperation proved to be those institutional network factors that have a significant influence on outsourcing. Those SMEs who have a stable relationship with local institutions are more likely to adopt outsourcing solutions. Our results suggest that in the case of SMEs the high degree of embedding, which is represented by cooperation with local institutions and the state, it is likely to weaken the international competitiveness of these in the long run, all the more so because none of the variables describing relational capabilities became significant in the result. 


\section{References}

Alguire, M. S.; Frear, C. R.; Metcalf, L. E. (1994). An examination of the determinants of global sourcing strategy. Journal of Business $\mathcal{F}$ Industrial Marketing 9(2): 62-74.

Andone, I. I.; Păvăloaia, V.D.W. (2010). Outsourcing the business services. Informatica Economică 14(1): 163.

Arbaugh, J. B. (2003). Outsourcing intensity, strategy, and growth in entrepreneurial firms. Journal of Enterprising Culture 11(02): 89-110.

Belso-Martínez, J. A. (2010). International outsourcing and partner location in the Spanish footwear sector. European Urban and Regional Studies 17(1): 65-82.

Bennett, R. J.; Robson, P. J. A. (1999). The use of external business advice by SMEs in Britain. Entrepreneurship \& Regional Development 11(2): 155-180.

Boşcor, D.; Băltescu, C. (2014). Romania's competitive advantage on the global outsourcing market. Bulletin of the Transilvania University of Brasov 7(56): 149-154.

Brewer, B.; Ashenbaum, B.; Ogden, J. A. (2013). Connecting strategy-linked outsourcing approaches and expected performance. International Journal of Physical Distribution \& Logistics Management 43(3): 176-204.

Espino-Rodríguez, T. F.; Rodríguez-Díaz, M. (2008). Effects of internal and relational capabilities on outsourcing: An integrated model. Industrial Management $\mathcal{\sigma}$ Data Systems 108(3): 328-345.

Gilley, K. M.; McGee, J. E.; Rasheed, A. A. (2004). Perceived environmental dynamism and managerial risk aversion as antecedents of manufacturing outsourcing: The moderating effects of firm maturity. Journal of Small Business Management 42(2): 117-133.

Görg, H.; Hanley, A. (2004). Does outsourcing increase profitability? The Economic and Social Review 35(3): 267-288.

Graf, M.; Mudambi, S. M. (2005). The outsourcing of IT-enabled business processes: A conceptual model of the location decision. Journal of International Management 11(2): 253-268.

Harland, C.; Knight, L.; Lamming, R.; Walker, H. (2005). Outsourcing: Assessing the risks and benefits for organisations, sectors and nations. International Journal of Operations \& Production Management 25(9): 831-850.

Heshmati, A. (2003). Productivity growth, efficiency and outsourcing in manufacturing and service industries. Journal of Economic Surveys 17(1): 79-112.

Jiang, B.; Qureshi, A. (2006). Research on outsourcing results: Current literature and future opportunities. Management Decision 44(1): 44-55.

Knudsen, M. P.; Servais, P. (2007). Analyzing internationalization configurations of SME's: The purchaser's perspective. Journal of Purchasing and Supply Management 13(2): 137-151. 
Kotabe, M.; Mol, M. J. (2009). Outsourcing and financial performance: A negative curvilinear effect. Journal of Purchasing and Supply Management 15(4): 205213.

Li, L.; Qian, G. (2007). Partnership or self-reliance: Prescriptions for small and medium-sized enterprises. Journal of Business Strategy 28(6): 29-33.

McIvor, R. (2009). How the transaction cost and resource-based theories of the firm inform outsourcing evaluation. Journal of Operations Management 27(1): 45-63.

Mohiuddin, M.; Su, Z. (2013). Manufacturing small and medium size enterprises' offshore outsourcing and competitive advantage: An exploratory study on Canadian offshoring manufacturing SMEs. Journal of Applied Business Research 29(4): 1111-1130.

Ngwenyama, O. K.; Sullivan, W. E. (2007). Outsourcing contracts as instruments of risk management. Journal of Enterprise Information Management 20(6): 615-640.

Solakivi, T.; Töyli, J.; Engblom, J.; Ojala, L. (2011). Logistics outsourcing and company performance of SMEs. Strategic Outsourcing: An International Journal 4(2): 131-151.

Stratman, J. K. (2008). Facilitating offshoring with enterprise technologies: Reducing operational friction in the governance and production of services. Journal of Operations Management 26(2): 275-287.

Teixeira, J. C. A. (2013). Outsourcing with long term contracts: Capital structure and product market competition effects. Review of Quantitative Finance and Accounting 42(2): 327-356.

Zineldin, M.; Bredenlöw, T. (2003). Strategic alliance: Synergies and challenges: A case of strategic outsourcing relationship "SOUR". International Journal of Physical Distribution \& Logistics Management 33(5): 449-464.

\section{Web Sources}

** $\mathrm{http}: / /$ www.outsourcingadvisors.ro/wp-content/uploads/2018/10/KPMGRomania-as-the-destination-for-SSCs-and-BPO.pdf 